This is the peer reviewed version of the following article: De Clercq, Dirk and Belausteguigoitia, Imanol (2019) Reducing the harmful effect of work overload on creative behaviour : buffering roles of energy-enhancing resources. Creativity And Innovation Management, 28(1), pp. 5-18., which has been published in final form at https://dx.doi.org/10.1111/caim.12278 . This article may be used for non-commercial purposes in accordance with Wiley Terms and Conditions for Use of Self-Archived Versions. 
Reducing the harmful effect of work overload on creative behavior: Buffering roles of energy-enhancing resources

Dirk De Clercq

Imanol Belausteguigoitia 


\title{
Reducing the harmful effect of work overload on creative behavior: Buffering roles of energy-enhancing resources
}

\begin{abstract}
This study investigates how employees’ perceptions of work overload might reduce their creative behaviors and how this negative relationship might be buffered by employees' access to three energy-enhancing resources: their passion for work, their ability to share emotions with colleagues, and their affective commitment to the organization. Data from a manufacturing organization reveal that work overload reduces creative behavior, but the effect is weaker with higher levels of passion for work, emotion sharing, and organizational commitment. The buffering effects of emotion sharing and organizational commitment are particularly strong when they combine with high levels of passion for work. These findings indicate how organizations marked by adverse work conditions, due to excessive workloads, can mitigate the likelihood that employees avoid creative behaviors.
\end{abstract}

Keywords: creative behavior; work overload; passion for work; emotion sharing; organizational commitment 


\section{Introduction}

An important path through which employees can contribute to organizational effectiveness is through their creative behaviors (Binyamin \& Carmeli, 2010; Castro, Gomes, \& de Sousa, 2012; Chen \& Kaufmann, 2008; Frederiksen \& Knudsen, 2017). Such behaviors generate new ideas that can improve the current organizational situation (Shalley \& Gilson, 2004; Son, Cho, \& Kang, 2017; Zhou \& George, 2001) and offer powerful benefits, such as when they add to the organization’s learning capacity (Oltra \& Vivas-López, 2013) or the implementation of positive change (Maimone \& Sinclair, 2014). Despite these beneficial effects, generating new ideas that improve the status quo can be challenging too, because other organizational members may consider the activities disruptive or threatening to their existing power bases (Hon, Bloom, \& Crant, 2014; Zhou \& George, 2001). For example, when creative employees suggest novel solutions to problems, other organizational members may resist to the extent that they feel threatened by the changes associated with those solutions (Yuan \& Woodman, 2010).

An important determinant of the likelihood to engage in creative behavior may be employees' perceptions of work overload, defined as their beliefs that work expectations are unreasonable or excessively harsh, due to impossible deadlines or time constraints (Altaf \& Awan, 2011). Some research suggests that work pressure can be motivational for employees’ creative endeavors — such that it reveals an inverted U-shaped (Baer \& Oldham, 2006; Binnewies \& Wörnlein, 2011) or even positive (Ohly \& Fritz, 2010) relationship_-but other studies indicate that employees' exposure to workplace adversity, in the form of excessive workloads, tends to steer them away from creative behaviors (Andrews \& Smith, 1996; Chen, Chang, \& Chang, 2015; Ocker, 2005; Soriano de Alencar \& Bruno-Faria, 1997; Vredenburgh \& He, 2003; Zhang, 
Zhang, \& Song, 2015). This ambiguity indicates the continued need to investigate contingencies that might inform the harmful effect of work overload on creative behavior, as well as how this effect might be contained (Aleksic, Mihelic, Cerne, \& Skerlavaj, 2017; Altaf \& Awan, 2011; Baer \& Oldham, 2006). Accordingly, we seek a better understanding of how employees’ negative responses to work overload, in the form of reduced creative behaviors, might be mitigated by relevant contingent factors.

To understand the circumstances in which perceptions of work overload might be less likely to diminish creative behaviors, we first acknowledge that excessive workloads may diminish creativity for both ability and motivation reasons (Amabile, 1996; Kobe \& Goller, 2009; Ma, Long, Zhang, Zhang, \& Lam, 2017). That is, exposure to excessive workloads could undermine employees' beliefs that they have the capability to contribute successfully to their organization's well-being through their creative activities, as well as thwart their intrinsic motivation to undertake these activities (Altaf \& Awan, 2011; Chen et al., 2015). In turn, we propose that the translation of work overload into reduced creative behavior might not be an automatic process but rather could be countered to the extent that employees have access to resources that spur their ability or desire to develop new ideas from which their organization can benefit (Bakker \& Xanthopoulou, 2013). Thus, we consider how resource access may be instrumental for preventing employees from responding negatively to excessive workloads, in the form of reduced creativity. This issue is especially pertinent for organizations that function in competitive external environments that require them to impose significant time pressures on their employees (Altaf \& Awan, 2011; Avery, Tonidandel, Volpone, \& Raghuram, 2010).

To anchor our theoretical arguments about the negative relationship between work overload and creative behavior, as well as the conditions in which work overload might be less 
likely to diminish such behavior, we rely on the job demands-resources (JD-R) model.

According to this model, demanding work conditions deplete employees' energy levels, such that employees turn away from positive work behaviors, but their access to relevant resources can mitigate or buffer this process (Bakker \& Demerouti, 2007; Pooja, De Clercq, \& Belausteguigoitia, 2016). Similarly, our baseline premise is that when employees believe they have insufficient time to do their job because of unrealistic deadlines, the resulting energy depletion inhibits their discretionary efforts aimed at creating new ideas (Chen et al., 2015; van Emmerik, Bakker, \& Euwema, 2009). However, we also propose that this negative relationship between work overload and creative behavior should be less salient to the extent that employees (1) feel passionate about their work, (2) are able to share their emotions with organizational colleagues, and (3) experience positive emotions of commitment toward their employer. Passion for work reflects the personal joy that employees derive from working hard (Baum \& Locke, 2004), emotion sharing is the extent to which employees can fully express their emotions with peers (Stephens, Heaphy, Carmeli, Spreitzer, \& Dutton, 2013), and organizational commitment (particularly its affective component) pertains to the emotional attachment that employees feel toward their organization (Meyer, Becker, \& Vandenberghe, 2004).

These three resources, conceptualized as moderators in our proposed model, align with the notion of positive psychology, according to which access to relevant resources provides employees with the energy needed to engage in positive work behaviors, despite the presence of workplace adversity (Seligman \& Csikszentmihalyi, 2000; Youssef \& Luthans, 2007). In particular, the glue that binds the three resources is that they instill positive energy in employees, which increases their ability and motivation to maintain some level of creativity even when they confront excessive workloads (Quinn, Spreitzer, \& Lam, 2012). Each moderator captures 
employees’ personal perceptions, but they also reflect sources of energy that may reside at different levels: Passion for work captures positive energy that employees possess internally (De Clercq \& Belausteguigoita, 2017a), emotion sharing captures positive energy derived from exchange relationships with peers (Stephens et al., 2013), and organizational commitment captures positive energy achieved because of how employees feel about their employing organization (Meyer et al., 2004). Accordingly, the consideration of these three contingency factors offers a consistent and comprehensive perspective on how employees' resource access may buffer against the likelihood that they refrain from creativity in the presence of excessive workloads (Bakker \& Demerouti, 2007; Pooja et al., 2016).

In short, we seek to contribute to previous research by investigating hitherto unexplored circumstances in which work overload is less likely to diminish creative behavior. In so doing, we respond to general calls to apply contingency approaches to the study of creativity (Huang, Hsieh, \& He, 2014, Pan, Sun, \& Chow, 2012; Zhou \& Pan, 2015), including the specific case in which employees suffer from excessive work pressures (Baer \& Oldham, 2006; Binnewies \& Wörnlein, 2011; De Clercq, Dimov, \& Belausteguigoitia, 2016). We postulate that employees’ negative reactions to excessive workloads, in the form of reduced creative behaviors, should be mitigated by their passion for work, emotion sharing, and organizational commitment. Together, these factors offer an extended view of how employees' access to selected resources can reduce the likelihood that they avoid creative behaviors when they are exposed to unfavorable work conditions due to excessive workloads (Schaufeli \& Bakker, 2004).

Moreover, we contribute to a better understanding of the link between work overload and creative behavior by investigating how the interplay among different resources influences employees' reactions to their work conditions, particularly resources that stem from employees' 
internal energy reservoirs (passion for work) and those derived from their relationships with external constituencies, whether individual colleagues (emotion sharing) or their employer (organizational commitment). In this sense, we explicitly acknowledge the interdependent effects of different resources for mitigating the negative influences of workplace adversity—an issue that has received relatively little attention in previous applications of the JD-R model (Bakker \& Demerouti, 2007; De Clercq \& Belausteguigoitia, 2017a). Although the external resources of emotion sharing and organizational commitment might diminish the harmful effects of work overload on creative behavior, the relative importance of these resources might increase to the extent that employees experience personal joy from leveraging these positive features to find novel solutions to excessive work demands due to their own passion for work.

\section{Theoretical Background}

Previous research calls for more investigations of how adverse work conditions steer employees away from positive work behaviors (Boyd, Bakker, Pignata, Winefield, Gillespie, \& Stough, 2011; Coelho, Augusto, \& Lages, 2011; Pooja et al., 2016). A critical example of a positive work behavior is the generation of new ideas that improve the current organizational situation, such that they offer novelty and usefulness (Son et al., 2017; Zhou \& George, 2001). Employees' engagement in such creative behaviors can be instrumental to both employees and their employer. For example, identifying novel working methods and creative solutions to organizational problems can fuel employees’ career success (Seibert, Kraimer, \& Crant, 2001) and career satisfaction, because of their enhanced ability to control and influence their work situation (Kim, Hon, \& Crant, 2009). Moreover, creating new ideas for improvement can stimulate organizational learning (Oltra \& Vivas-López, 2013) and invoke positive organizational change (Maimone \& Sinclair, 2014). 
Despite these beneficial effects, change-invoking work behaviors that suggest creative solutions to problem areas can consume a great deal of employees' energy, especially if other organizational members disagree about the adequacy of the proposed solutions (Van Dijk \& Van Dick, 2009; Zhou \& George, 2001) or exhibit strong resistance, which should be greater to the extent that they fear that the solutions will undermine their own reputation or can be directly tied to them (Buchanan \& Badham, 1999; Yuan \& Woodman, 2010). In light of these challenges, it is important to understand how demanding work conditions, such as excessive workloads, could steer employees away from creative behaviors. Previous research on creativity drivers highlights the enabling role of positive factors but devotes less attention to the inhibitive role of adverse work situations; as exceptions, some research notes the harmful influences of role ambiguity (Coelho et al., 2011), perceived organizational politics (Spreitzer, Porath, \& Gibson, 2012), or extreme workloads (Chen et al., 2015). We focus on this latter source of workplace adversity, which refers to the extent to which employees suffer from unrealistic expectations in terms of time constraints and work pace (Altaf \& Awan, 2011)

In particular, we draw from the JD-R model to understand how and when perceptions of work overload might reduce creative behaviors, as well as the circumstances in which this process is less likely. According to this framework, workplace adversity depletes employees’ energy levels, which may spill over to a reduced propensity to engage in positive work behaviors (Bakker \& Demerouti, 2007; van Emmerik et al., 2009). However, JD-R theory also posits that the negative, energy-depleting effect of workplace adversity is less salient when employees have access to energy-enhancing resources (Pooja et al., 2016; Xanthopoulou, Bakker, Demerouti, \& Schaufeli, 2007), whether these resources stem from their personal characteristics or their relationships with external entities (Schaufeli \& Bakker, 2004). In the presence of such 
resources, demanding work conditions are less likely to turn employees away from positive work behaviors, because the resources function as protection or "buffers" against this impact (Bakker \& Demerouti, 2007). We focus on the buffering roles of three resources: passion for work, emotion sharing with colleagues, and affective commitment to the organization. We postulate that when employees can draw from these resources, they are both more able and more motivated to deal with the hardships that stem from significant work overloads (Altaf \& Awan, 2011; Russ-Eft, 2001), so it becomes less likely that they refrain from generating novel ideas that could benefit their organization (Bakker \& Demerouti, 2007). We also predict that the usefulness of the two resources that stem from employees' relationships with other constituents (emotion sharing and organizational commitment) for buffering the work overload-creative behavior relationship increases when employees can rely on their internally driven passion for work. The conceptual framework detailing these predictions is in Figure 1. In the next section, we explain the arguments underlying each of its constitutive hypotheses.

\section{[Insert Figure 1 about here]}

\section{Hypotheses}

\section{Work Overload and Creativity}

Our baseline hypothesis pertains to the negative relationship between employees' perceptions about work overload and their creative behavior. Although severe work demands, including high time pressure, might not automatically generate negative outcomes (Baer \& Oldham, 2006; Unsworth \& Clegg, 2010), previous research generally indicates that excessive workloads cause significant frustration in employees (Altaf \& Awan, 2011; Russ-Eft, 2001), thereby undermining their propensity to undertake positive work behaviors (Chen et al., 2015; Ocker, 2005; Zhang et al., 2015). In this study, we explicitly acknowledge that exposure to 
excessive workloads diminishes both the ability and the motivation of employees to engage in creative behaviors.

First, when employees have to deal with unrealistic workloads, they become distressed and experience a drain on their energy levels (Altaf \& Awan, 2011; Quinn et al., 2012), such that they have less ability to contribute to their organization's success through positive work behaviors (Pooja et al., 2016; Paillé, 2011

), including the development of new ideas that could lead to organizational improvement (Zhang et al. 2015). Such ideas often are disruptive and invoke organizational change, so they may provoke strong resistance from other members who feel threatened by the disruptions (Yuan \& Woodman, 2010; Zhou \& George, 2001). The energy-depleting effect of work overload thus may thwart employees’ creative behaviors, even if these behaviors would benefit their organization, because they lack the time or stamina to develop and defend their new ideas (Quinn et al., 2012; Zhang et al., 2015). Conversely, when they are unencumbered by excessive workloads, employees have greater ability to allocate their discretionary energy to creative activities.

Second, the severe demands on their time in the presence of excessive workloads may thwart employees' intrinsic motivation to develop new ideas from which their organization can benefit (Amabile, 1996; Chen et al., 2015). Employees tend to be less excited about the possibility of contributing to organizational effectiveness through positive work behaviors to the extent that they believe that their organization imposes unrealistic time pressures and deadlines on them (Pooja et al., 2016). This demanding work situation may be interpreted as a signal of disrespect for their work or contributions, such that they believe their organization does not deserve to benefit from their creative efforts (Chen et al., 2015). In contrast, if employees 
perceive that their workload is reasonable, the associated sense of organizational respect tends to make them more excited about their work situation (Altaf \& Awan, 2011), so their propensity to develop new ideas that contribute to organizational effectiveness should increase.

Hypothesis 1: There is a negative relationship between employees' perceptions of work overload and their creative behavior.

\section{Moderating Role of Passion for Work}

We predict a buffering effect of passion for work on the negative relationship between perceptions of work overload and creative behavior. Employees who are passionate about their work experience joy and excitement when executing their jobs (Vallerand et al., 2003), and these positive emotions enable them to engage in a variety of job tasks, including those that may spark organizational resistance (Quinn et al., 2012). Thus, the positive emotions that come with their passion for work should increase employees' ability to cope with the stress of having to meet their job requirements in the presence of significant time constraints (Bakker \& Demerouti, 2007; Altaf \& Awan, 2001), such that they can maintain some residual energy to develop new ideas (Baum \& Locke, 2004), Conversely, employees with a low passion for work are less likely to have the ability to undertake extraordinary efforts in the presence of stringent time pressures (Ho, Wong, \& Lee, 2011), so they focus on the status quo rather than going out of their way to contribute to their organization's well-being by performing creative behaviors.

Employees' passion for work also might mitigate their lack of motivation to engage in creative behavior in the presence of excessive workloads because they enjoy the challenge of performing adequately in such adverse conditions (De Clercq \& Belausteguigoitia, 2017a; Vallerand et al., 2003). That is, passion for work may mitigate the potency with which employees’ perceptions of work overload reduce their creative behavior, because the challenge 
of coping with severe time constraints in the execution of their daily jobs and finding novel solutions to deal with the workplace adversity may be attractive to them (Baer \& Oldham, 2006). In contrast, when employees experience limited passion for their work, they tend to be more passive in their job execution (Baum \& Locke, 2004) and may be more indifferent to the possibility of generating novel ideas that could improve their organization in the presence of excessive workloads.

Hypothesis 2: The negative relationship between employees' perceptions of work overload and creative behavior is moderated by their passion for work, such that the relationship is weaker at higher levels of passion for work.

\section{Moderating Role of Emotion Sharing}

The extent to which employees can freely share their emotions with their colleagues also should attenuate the negative effect of their perceptions of work overload on their creative behaviors. Emotion sharing enables employees to control and subdue the stress that comes with unrealistic work demands, because they can reach out to others and learn how those others have coped with the demands (Stephens et al., 2013). Peer relationships marked by high levels of emotion sharing also infuse employees with positive energy by creating feelings of psychological safety (Quinn et al., 2012), such that it becomes less likely that the energy depletion that they experience due to excessive workloads prevents them from undertaking creative behaviors. Conversely, in the absence of open emotion sharing, employees receive less support from colleagues in terms of how to cope with adverse work conditions (Morris \& Keltner, 2000). In this case, the energy depletion associated with excessive workloads likely grows stronger (Avery et al., 2010; Altaf \& Awan, 2011), with particularly salient and harmful effects on their ability to generate new ideas. 
Moreover, when employees feel comfortable expressing their concerns about how excessive workloads may undermine their organizational functioning, they may gain reassurance from their collaborative colleagues that such a fear is unjustified (Stephens et al., 2013), which should help them suppress negative emotions of frustration that otherwise would steer them away from productive work behaviors such as creativity (Bakker \& Demerouti, 2007). Similarly, the emotional support that employees experience through their social exchanges with colleagues, including the realization that they are not alone in having to cope with heavy workloads and the associated feeling of "being in the same boat" (Pooja et al., 2016; Stephens et al., 2003), may fuel positive energy that diminishes the likelihood that work overload diminishes creative behavior. Therefore, employees should be less likely to respond to excessive workloads in the form of lower creativity to the extent that they can freely share their emotions with organizational peers.

Hypothesis 3: The negative relationship between employees' perceptions of work overload and creative behavior is moderated by their emotion sharing, such that the relationship is weaker at higher levels of emotion sharing.

\section{Moderating Role of Organizational Commitment}

We hypothesize a similar beneficial role of organizational commitment. First, the buffering role of organizational commitment might be explained by the increased information sharing that it fuels among employees and associated ability to deal with excessive workloads (De Clercq, Dimov, \& Thongpapanl, 2010). Employees who exhibit a strong attachment to their organization are more likely to reach out to colleagues and ask for their advice about how to cope with workplace adversity, because this attachment increases employees' motivation to apply their collective knowledge bases to finding solutions (Van den Hooff \& Van Weenen, 2004). Enhanced information sharing also can generate additional insights into why the 
organization imposes strict deadlines on its employees and thus mitigate the energy depletion that tends to come with excessive workloads (Bakker \& Demerouti, 2007). Thus, organizational commitment should mitigate the likelihood that severe time pressures turn employees away from positive creative behaviors, because employees have a greater ability to understand why such time pressures might not be necessarily harmful.

Further, employees who feel a strong emotional bond to their organization perceive their work environment as safer and more supportive (Uçanok \& Karabati, 2013) and accordingly are more likely to accept the practices that their organization employs, even if these practices are stressful and seem to undermine their ability to perform their job adequately (Meyer et al., 2004). Thus, organizational commitment should help counter the decline in employees' motivation to contribute to their organizations' well-being in response to excessive workloads (Chen et al., 2015), such that it mitigates the likelihood that work overload turns employees away from positive work behaviors such as creativity. Similarly, high levels of organizational commitment shift employees’ focus, from expecting personal comfort while meeting their job requirements to enhancing organizational effectiveness in general (Meyer et al., 2004). Highly committed employees accordingly should assign relatively less weight to the hardships associated with having insufficient time to perform their jobs and feel more motivated to maintain some level of creativity, even in the presence of excessive workloads.

Hypothesis 4: The negative relationship between employees' perceptions of work overload and creative behavior is moderated by their organizational commitment, such that the relationship is weaker at higher levels of organizational commitment.

\section{Three-Way Interaction Effects}

Finally, the buffering effects of the resources that derive from employees' relationships with their individual colleagues (emotion sharing) or employer in general (organizational 
commitment) may be invigorated by the internal resource of passion for work, suggesting threeway interaction effects. We have suggested that at higher levels of emotion sharing and organizational commitment, the diminished likelihood that work overload translates into reduced creative behavior may be explained, at least in part, by the presence of enhanced information sharing among employees. Employees who can rely on strong peer relationships or experience a strong emotional bond with their organization are better able to cope with the energy depletion due to work overload, because of the insights that result from their associated information sharing (De Clercq et al., 2010; Stephens et al., 2013). But in addition, employees' ability to draw from these relational resources should be particularly useful for coping with excessive workloads when their own passion for work also is high. To the extent that employees are passionate about working hard, they should be particularly prone to leverage any insights gained from their exchanges with other organizational members, in terms of finding solutions to the threats of excessive workloads, because they derive personal joy from such efforts (Baum \& Locke, 2004). A strong passion for work then should stimulate employees to allocate significant efforts to combining their own insights with those of organizational colleagues and finding ways to cope with severe workplace adversity, such as excessive workloads (Ho et al., 2011). These efforts in turn should reduce the energy depletion that they experience in the presence of work overload (Russ-Eft, 2001) and further decrease the likelihood that they turn away from creative behaviors in response to this unfavorable work condition.

Hypothesis 5: The buffering effect of emotion sharing on the negative relationship between employees' perceptions of work overload and creative behavior is moderated by their passion for work, such that the buffering effect is stronger at higher levels of passion for work.

Hypothesis 6: The buffering effect of organizational commitment on the negative relationship between employees' perceptions of work overload and creative behavior is moderated by 
their passion for work, such that the buffering effect is stronger at higher levels of passion for work.

\section{Method}

\section{Sample and Data Collection}

We collected data from employees working for a Mexican-based organization that operates in the smelting industry and produces custom-made steel parts for heavy machinery and equipment. ${ }^{1}$ By focusing on a single organization, we avoided the presence of unobserved differences in terms of how external competitive pressures may influence the likelihood that employees generate new ideas targeted at improving the status quo (Dayan \& Di Benedetto, 2011). Notably, the organization's external competition features both local and foreign companies competing for market share in a relatively stable industry, which imposes strong pressures on employees to work hard and give their utmost to help their company maintain its competitive positioning. Therefore, this empirical context is relevant for investigating how excessive workloads might translate into reduced creative behaviors, as well as how this process may be contained by employees’ access to relevant resources.

The data collection entailed two separate surveys. First, we asked 120 randomly selected employees to assess the extent to which they experienced excessive workloads in executing their daily work, felt passion about their work, and could freely talk about their emotions with colleagues, as well as how they felt about their organization in general. The organization's top management strongly endorsed this study, which enabled us to receive 109 responses, reflecting a 91\% response rate. Second, we contacted the immediate supervisors of each first-round respondent separately and asked them to assess their employees’ creative behavior. The

\footnotetext{
${ }^{1}$ This study is part of a larger research project that also sought to explain work behaviors such as organizational citizenship (De Clercq \& Belausteguigoitia, 2017b) and voice (De Clercq \& Belausteguigoitia, 2017c).
} 
participating employees had either primarily operational responsibilities (production, packaging, quality control) or more supportive functions (planning, accounting, sales). The average respondent was 34 years of age and had worked for the organization for 7 years; 36\% were women, $71 \%$ worked in an operational function, and $36 \%$ had managerial responsibilities (i.e., other employees reported to them).

To avoid social desirability or acquiescence biases, we guaranteed the participants complete confidentiality, repeatedly indicated that there were no correct or incorrect answers, and asked them to answer the questions as honestly as possible (Spector, 2006). The surveys were administered in Spanish, so we relied on Brislin, Lonner, and Thorndike’s (1973) translation procedure: After a bilingual management professor had translated the English version of the surveys into Spanish, another bilingual professor translated them back into English. We compared the original and back-translated English versions and resolved any discrepancies.

\section{Measures}

The five focal constructs were based on previous research and measured on seven-point Likert scales, ranging from 1 (“strongly disagree”) to 7 (“strongly agree”). Table 1 provides an overview of the different items that were used to measure the focal constructs.

[Insert Table 1 about here]

Creative behavior. In the separate survey distributed to supervisors, we measured their assessments of their employees' creative behavior, using four items based on previous research (Janssen, 2001). An example item is: "This employee often creates new ideas for improvement" (Cronbach’s alpha $=.79)$. 
Work overload. In the employee survey, we used four items from previous research to measure their sense of work overload (Janssen, 2001; Van Veldhoven \& Meijman, 1994), such as “I often have to work too fast” (Cronbach's alpha $=.82)$.

Passion for work. We measured employees' passion for work with four items based on previous studies (Baum \& Locke, 2004). For example, respondents indicated whether "I derive most of my life satisfaction from my work” (Cronbach’s alpha $=.84)$.

Emotion sharing. To assess the extent to which employees could openly share their emotions with organizational colleagues, we relied on Stephens et al.'s (2013) three-item measure of emotional carrying capacity. One example item is: "I can fully express my emotions to my colleagues” (Cronbach’s alpha $=.71)$

Organizational commitment. We assessed employees’ level of organizational commitment with five items drawn from Meyer and Allen (1991). The respondents indicated, for example, whether "I really feel the problems of the company like they are my own" (Cronbach's alpha $=.79)$.

Control variables. To account for alternative explanations of employee creative behavior, we controlled for three demographic characteristics: age, gender, and organizational tenure, consistent with previous research (Gong, Huang, \& Farh, 2009). Furthermore, we controlled for employees' job function, that is, whether their responsibilities were primarily operational (i.e., related to physical production) or more supportive, using the former as the base category. Finally, we controlled for their hierarchical level (dummy variable set to 1 when other employees report to the respondent).

A confirmatory factor analysis of a five-factor model revealed significant factor loadings for each the construct items ( $\mathrm{t}$ > 2.0; Lattin, Carroll, \& Green, 2003), indicating convergent 
validity. As evidence of discriminant validity, we found significant differences between the chisquare values of the constrained model (correlation between any two constructs set to equal 1) versus the unconstrained model (correlation between constructs set free) for all ten construct pairs $\left(\Delta \chi^{2}(1)>.3 .84\right)$, including the pair that includes the two relation-based resources of emotion sharing and organizational commitment. We conducted two further tests to assess the possibility of common method bias, because the measures of the independent and moderator constructs came from the same respondents at the same point in time (though the dependent variable was measured separately). First, according to Harman’s single-factor test (Podsakoff \& Organ, 1986), if common method bias were an issue, a single factor that included all four constructs—work overload, passion for work, emotion sharing, and organizational commitment—would account for most of the variance in the data. The first factor explained only $32 \%$ of the variance, so this bias does not appear to be a significant concern. Second, a confirmatory factor analysis in which each item of the four constructs loaded on a single factor produced a significantly worse fit than that of a four-factor model $\left(\Delta \chi^{2}(6)=318.60, p<.001\right)$, which further mitigates concerns about common method bias (Lattin et al., 2003).

\section{Results}

Table 2 shows the zero-order correlations and descriptive statistics, and Table 3 reports the regression results. Model 1 included the control variables, Model 2 added work overload, and Model 3 added the three moderators: passion for work, emotion sharing, and organizational commitment. Models 4-6 each added one of the interaction terms separately: work overload $\times$ passion for work, work overload $\times$ emotion sharing, and work overload $\times$ organizational commitment, respectively. Accordingly, Models 4-6 assess the additional explanatory power of each individual interaction term, compared with the baseline Model 3 that only includes the main 
effects. As previous research suggests, it is appropriate to include multiple interaction terms separately, because the simultaneous inclusion of multiple interaction terms in a single model can mask true moderating effects (Aiken \& West, 1991; Covin, Green, \& Slevin, 2006; De Clercq et al., 2010; Zahra \& Hayton 2008). Finally, Models 7 and 8 added the three-way interaction terms (work overload $\times$ emotion sharing $\times$ passion for work and work overload $\times$ organizational commitment $\times$ passion for work, respectively), together with the two corresponding sets of constitutive two-way interactions, as recommended by Aiken and West (1991). For both the two- and three-way interaction terms, we adopted the well-established approach and mean centered the product terms (Aiken \& West, 1991).

[Insert Tables 2 and 3 about here]

The results in Model 1 showed a positive relationship between organizational tenure and creative behavior, indicating that employees who have worked for their organization for a longer time may feel more confident about their abilities to generate new ideas that can improve the organizational status quo (Amabile, 1996; Gong et al., 2009). In support of our baseline prediction that excessive workloads diminish the propensity to generate new ideas, Model 2 revealed that work overload related negatively to creative behavior $(\beta=-.332, p<.01)$, in line with Hypothesis 1. Although outside the theoretical focus of this study, the results in Model 3 also indicated direct positive effects of passion for work $(\beta=.146, p<.10)$, emotion sharing $(\beta=$ $.226, p<.05)$, and organizational commitment $(\beta=.181, p<.05)$ on creative behavior. The relative weak positive direct effect of passion for work, compared to that of the other moderators, suggests that resources which relate to how employees feel about their organizational environment (emotion sharing with peers, and positive feelings about their employing 
organization in general) are more prominent drivers of organization-improving, creative behaviors than resources which employees possess internally.

Models 4-6 supported the hypothesized buffering effects of passion for work ( $\beta=.124, p$ $<.01)$, emotion sharing $(\beta=.258, p<.01)$, and organizational commitment $(\beta=.198, p<.01)$ on the negative relationship between work overload and creative behavior. The likelihood that increasing levels of work overload would diminish creative behavior decreased when employees could rely on their passion for work (Hypothesis 2), could openly exchange emotions with colleagues (Hypothesis 3), or felt a strong emotional connection with their organization (Hypothesis 4). To clarify the nature of these interactions, we plotted the effects of work overload on creative behavior for high and low levels of the three moderators in Figure 2, Panels A to C, combined with a simple slope analysis for each (Aiken \& West, 1991). The results of the simple slope analysis indicated that the relationship between work overload and creative behavior was negative at low levels of passion for work ( $\beta=-.302, p<.01)$, emotion sharing ( $\beta$ $=-.392, p<.01)$, and organizational commitment $(\beta=-.355, p<.01)$, but it became nonsignificant at high levels of these moderators ( $\beta=-.054, \beta=.124, \beta=.041$, respectively, all $n s)$.

[Insert Figures 2A-C about here]

Moreover, we found support for Hypothesis 5 in the positive three-way interaction among work overload, emotion sharing, and passion for work in Model $7(\beta=.093, p<.05)$. The buffering (or positive moderating) effect of emotion sharing on the negative work overloadcreative behavior relationship was stronger at higher levels of passion for work. To clarify this interaction, we plotted the moderating effect of emotion sharing on the work overload-creative behavior relationship at high versus low levels of passion for work in Figure 3, Panels A and B, and we assessed the slope differences (Dawson \& Richter, 2006). The slope difference in Figure 
3, Panel A, was more significant $(\mathrm{t}=3.339, p<.001)$ than that in Panel B $(\mathrm{t}=2.181, p<.05)$, in support of Hypothesis 5. The results for Hypothesis 6 mirrored those of Hypothesis 5. The buffering effect of organizational commitment on the work overload-creative behavior relationship was stronger at higher levels of passion for work $(\beta=.062, p<.05)$, and Figure 4 , Panels A and B, showed similar patterns to their counterparts in Figure 3, Panels A and B. The slope difference in Figure 4, Panel A, was more significant $(\mathrm{t}=3.617, p<.001)$ than in Panel B $(\mathrm{t}=2.148, p<.05)$, consistent with Hypothesis 6 .

[Insert Figures 3A-B and 4A-B about here]

Because of the relatively small sample size, we also performed a post hoc power analysis, using G*Power (Faul, Erdfelder, Lang, \& Buchner, 2007), to assess whether the application of multiple regression analysis was appropriate. To obtain a standard power level of .80 for a multiple regression model with ten predictors_-gender, age, organizational tenure, job function, hierarchical level, work overload, passion for work, emotion sharing, organizational commitment, and work overload $\times$ passion for work — combined with an effect size equivalent to Cohen's $\mathrm{f}^{2}=92$ (or $\mathrm{R}^{2}=.48$ in Model 4 in Table 3), the sample size must be at least 50 . With our sample size of 109, we achieved a power level of almost 100\% (Faul et al., 2007). Similar results applied to the other regression models in Table 3. Thus, our sample was sufficiently large to generate adequate statistical power levels for our multiple regression analyses.

\section{Discussion}

\section{General Findings}

Drawing on the JD-R model (Bakker \& Demerouti, 2007), we have investigated how employees' access to the three pertinent resources_-passion for work, emotion sharing, and organizational commitment-might suppress negative responses to work overload, such as 
reduced creative behavior. We also argue that the potency with which emotion sharing and organizational commitment diminish the negative influence of work overload is particularly strong among employees who are more passionate about their work. The results generally support these theoretical claims.

The direct negative relationship between work overload and creative behavior is in line with previous research on the harmful role of adverse work conditions for positive work behaviors (Boyd et al., 2011; Paillé, 2011; Pooja et al., 2016; Spreitzer et al., 2012). Excessive workloads drain employees’ energy (Altaf \& Awan, 2011) and undermine their ability and motivation to engage in productive work behaviors, such as creativity (Amabile, 1996; Chen et al., 2015). In particular, the belief that there is not enough time available to do their jobs creates significant stress for employees, because of the uncertainty about whether they can execute their job tasks successfully (Russ-Eft, 2001) and undertake the efforts needed to counter possible organizational resistance to their new ideas (Yuan \& Woodman, 2010). Significant time constraints thus undermine employees’ capacity beliefs with regard to creative endeavors (Avery et al., 2010; Unsworth \& Clegg, 2010). Moreover, employees may interpret persistent work overload as disrespectful or even offensive, and the associated negative emotions that they experience may fuel their tendency to refrain from positive creative behaviors that otherwise could benefit their organization (Chen et al., 2015).

The negative effect of work overload on creative behavior also depends on employees’ access to critical, energy-enhancing resources, which derive from their personal characteristics (passion for work), relationships with colleagues (emotion sharing), or feelings about their employing organization (organizational commitment). The buffering roles of these factors follow the JD-R argument that the relative importance of adverse, energy-draining work conditions for 
reducing positive work behaviors diminishes in the presence of relevant resources (Bakker \& Demerouti, 2007; Pooja et al., 2016; Xanthopoulou et al., 2007). Employees are less likely to channel any negative energy that they might experience due to excessive workloads into reduced creativity when they (1) derive personal joy from working hard, (2) feel comfortable sharing their emotions with peers, and (3) feel a strong attachment to their organization.

\section{Theoretical Implications}

The support we find for the negative relationship between work overload and creative behavior aligns with previous findings on the harmful effect of excessive work pressures on employees’ propensity to develop new ideas for organizational improvement (Chen et al., 2015; Ocker, 2005; Vredenburgh \& He, 2003; Zhang et al., 2015). This finding also is interesting in light of previous studies that reveal that increasing work pressure might spur creativity, up to a certain point, such that this pressure can function as a "challenge stressor" that stimulates employees’ creativity (Baer \& Oldham, 2006; Ohly, Sonnentag, \& Pluntke, 2006). In a post hoc test, we checked for this inverted U-shaped relationship among our sample but did not find evidence of it. This difference might arise from our measure of employees’ perceptions of time pressure in general, not specifically the pressure to perform creative behaviors. For example, Unsworth and Clegg (2010), in their qualitative study of creativity among design engineers, find that employees' engagement in creative behaviors increases when they experience both time scarcity and strong organizational pressures to be creative. Continued studies thus might apply a broader set of measures of work overload, to distinguish the overall amount of time pressure that employees experience at work from the extent to which they experience pressure specifically with respect to creativity (Baer \& Oldham, 2006). 
The core contribution of this study lies in its elaboration of how three energy-enhancing resources—passion for work, emotion sharing, and organizational commitment—buffer the negative effect of employees’ perceptions of work overload on their creative behaviors. The lack of previous attention to this influence is somewhat surprising, in light of the recognition that the energy-depleting effects of demanding work conditions that make employees turn away from positive work behaviors can be countered by access to relevant resources (e.g., Bakker, Demerouti, \& Euwema, 2005; Hakanen, Bakker, \& Demerouti, 2005; Pooja et al., 2016), as well as calls for continued considerations of contingency factors that might influence the extent to which workload pressures inform creativity (e.g., Aleksic et al., 2017).

Employees who score high on the passion for work measure derive joy from working hard, such that they are less sensitive to the energy-depletion effect of excessive workloads (Baum \& Locke, 2004). The enhanced energy associated with this passion offsets the reduced confidence about organizational functioning that tends to arise when people confront unrealistic work demands, so the likelihood that excessive workloads translate into the lower behaviors gets thwarted (Bakker \& Demerouti, 2007). Moreover, employees who score high on passion for work derive some satisfaction from coping with challenging work situations (Vallerand et al., 2003), so they may enjoy finding novel ways to deal with excessive workloads. As result, their motivation to maintain some level of creativity, even in the presence of excessive workloads, is stimulated.

The buffering effect of emotion sharing shows that the desire to refrain from creative behaviors as a reaction to unrealistic work demands is lower to the extent that employees feel comfortable sharing their emotions with peers (Stephens et al., 2013). When employees receive emotional support from their colleagues in the presence of excessive workloads, it becomes less 
likely that they feel incapable of undertaking these positive, creative work behaviors. The chances to share the personal hardships that come with work overload, and the associated feelings of a shared fate, may also have a motivational component, such that it is less likely that employees' frustration with their work overload escalates and leads them to refuse to help their organization by being creative (Altaf \& Awan, 2011; Morris \& Keltner, 2000). Conversely, at low levels of emotion sharing, employees receive less support in their endeavors to cope with work overload and cannot easily express their frustration, so refraining from positive creative behaviors becomes more likely in response to this negative work situation.

Organizational commitment also functions as protection against the energy-depleting effect that results from excessive workloads. The information sharing that organizational commitment promotes among employees (De Clercq et al., 2010) can provide critical insights into effective ways for dealing with challenging deadlines. Furthermore, information sharing may facilitate understanding of why it could be impossible for the organization to provide its employees with unlimited time to perform their jobs, such as when it faces strong external competitive pressures (Altaf \& Awan, 2011). Organizational commitment facilitates the acceptance of unfavorable practices (Meyer et al., 2004), so employees more readily tolerate excessive workloads and do not use the accompanying hardship as an excuse to halt their creative behaviors.

Finally, this study's findings add to creativity research by revealing the interdependence of different resources in mitigating the negative consequences of adverse work conditions (Schaufeli \& Bakker, 2004). The usefulness of the two resources that reside in employees' relationships with either individual colleagues or the employing organization in general (emotion sharing and organizational commitment, respectively) for countering the harmful effects of 
excessive workloads is particularly high when employees have a strong passion for work; conversely, these two resources are less useful when passion for work is low. On the one hand, when their passion for work is high, employees derive personal joy from their enhanced interactions with organizational peers, through emotion sharing and organizational commitment (Vallerand et al., 2003), so these two positive features can be leveraged maximally to find effective ways to deal with excessive workloads. On the other hand, when their passion for work is low, employees gain less joy from exerting strong efforts to leverage strong relationships with peers or the organization in general to cope with excessive workloads. Their frustration with unrealistic deadlines thus increases (Altaf \& Awan, 2011), and their propensity to help their organization with creative behaviors diminishes.

A closer inspection of the three-way interaction plots also indicates a positive relationship between work overload and creative behavior when high levels of emotion sharing or organizational commitment are combined with a strong passion for work (Figures 3A and 4A, respectively). Perhaps employees who can draw from both relational and internal resources interpret increasing workloads as challenge stressors that spur them to find creative solutions for the pressures that they experience (Ohly \& Fritz, 2010). This interpretation warrants caution though, in light of its post hoc nature. Future studies could investigate how the ways in which employees experience extreme work pressures may depend on different resource configurations to which they have access (Payne, 2006).

Overall, our results provide a more complete understanding of when severe time constraints and unrealistic deadlines are more or less likely to steer employees away from generating new ideas that could help their organization. In particular, the results contribute to extant creativity literature by specifying the concurrent roles that work overload and different, 
understudied resources play in influencing creative behaviors, revealing both individual and collective mitigating influences of these resources on the likelihood that work overload thwarts such behaviors.

\section{Practical Implications}

This study of the interplay of work overload with employees’ resource access to predict creative behavior has great practical significance. The belief that insufficient time is available to perform their jobs successfully can be a significant source of frustration for employees, and organizations should seek strategies to diminish its occurrence. Significant in this regard is the possibility that some employees may be hesitant to admit that the pace of work is too fast for them, to avoid looking incompetent or receiving less meaningful job assignments (Avery et al., 2010). Organizations thus must be proactive in identifying reasons that employees might believe their workloads are unrealistically high. They also could create specific guidelines related to the means and ends of employees' job requirements, particularly for organizational newcomers (Saks, Uggerslev, \& Fassina, 2007). Training efforts during socialization programs for new hires, for example, might emphasize both expected performance outcomes and different ways to achieve them, to increase these new employees' ability to achieve adequate performance and retain energy for developing new ideas that can improve the organization, even in the presence of stringent time requirements.

Moreover, this study indicates that employees who feel passionate about their work may be better prepared to cope with excessive workloads. Passion for work thus provides an important means that organizations eager to stimulate creativity can use to mitigate the problems of excessive workloads. Passionate people tend to be more involved in their work, which gives them a greater ability and motivation to deal with unrealistic timelines and cope with the 
associated stress, and these features ultimately can be beneficial for increasing the organization's creative profile. To increase the likelihood that current and future employees exhibit a strong passion for work, organizations could demonstrate how that passion can help resolve a wide range of organizational problems, particularly those that employees are most interested in at a personal level.

To decrease the risk that excessive workloads undermine employees' creative efforts, organizations also could stimulate the development of positive energy about their surrounding environment, by fostering close peer relationships that make employees feel comfortable sharing their personal concerns with one another and by creating an organizational culture that stimulates the collective good instead of individual interests. Such positive energy stimulates information sharing among employees (De Clercq et al., 2010), which in turn helps reduce the hardships of excessive workloads. That is, employees who can count on the support of their colleagues or employer likely gain more insights into how to do their jobs effectively, even in the presence of excessive workloads, which should lower their propensity to refrain from positive behaviors such as creativity. Conversely, when employees feel a weak connection with their peers or employer, they may be less prone to reach out to or learn from others about how to cope with excessive workloads. Therefore, the training and evaluation of employees should be based, at least in part, on whether they are open to sharing their feelings with other organizational members and prone to contribute to the organizational collective rather than their personal interests.

\section{Limitations and Future Research}

We acknowledge that this study has some shortcomings that suggest research opportunities. First, we did not measure the causal mechanisms that underlie the hypothesized relationships. We argued that exposure to excessive workloads depletes employees' energy 
levels, which may reduce their ability and motivation to dedicate significant efforts to creativity. Similarly, high levels of passion for work, emotion sharing, and organizational commitment were argued to have a mitigating effect on the diminished ability and motivation for creativity in response to work overload. Additional research might measure these mechanisms directly and investigate, for example, whether the ability- or motivation-based mechanisms are more prevalent.

Second, some caution is warranted about the possibility of reverse causality; some employees might reduce their workloads because of their creative behaviors. Our hypotheses are anchored in the well-established JD-R model (Bakker \& Demerouti, 2007), but continued research could apply longitudinal designs to investigate explicitly the time-based processes that link work overload with creative behavior, as well as the contingency factors that inform this process. A related limitation is our reliance on self-reported data to measure the study's variables; further studies could collect secondary data on creative behavior, such as company records about the number and quality of new ideas that employees propose.

Third, by focusing on three specific contingency factors, we ignore other potential buffers of the negative relationship between work overload and creative behavior. Other internal factors that could function as buffers against the energy-draining effect of excessive workloads include employees' psychological capital in the form of self-efficacy, hope, optimism, and resilience (Avey, Luthans, \& Youssef, 2010), their tenacity (Baum \& Locke, 2004), or their political savvy (Ferris, Perrewé, Anthony, \& Gilmore, 2000)—factors that may facilitate the identification of internal stakeholders who can offer advice about how to achieve adequate job performance despite excessive workloads. Potentially influential organizational factors could include the extent to which employees believe that decision-making procedures are fair (Colquitt, Conlon, 
Wesson, Porter, \& Ng, 2001) or that their organization provides adequate rewards for new ideas (De Clercq, Castañer, \& Belausteguigoitia, 2011).

Fourth, an empirical weakness of this study is its relatively small sample size and reliance on one organization. These features might limit the generalizability of the results. Even though a post hoc power analysis indicated that our sample is sufficiently large for our multiple regression analysis (Faul et al., 2007)—and smaller sample sizes can provide more conservative statistical tests of theoretical relationships, particularly for conceptual models that include interaction effects (Bouckenooghe, De Clercq, \& Deprez, 2014)—future research still may benefit from larger samples. Similarly, our theoretical arguments are not industry specific, but our singleorganization design prevents us from investigating the role of potentially relevant industry factors, such as the level of competitive rivalry (Porter, 1996). Competitive rivalry might make employees more willing to accept the hardships that come with excessive workloads (Lahiri, Pérez-Nordtvedt, \& Renn, 2008), which in turn may influence the negative effect of this adverse work condition on their creative behavior. Future research endeavors therefore could test this study’s conceptual framework across different industries.

Fifth and finally, this study is based on a Mexican organization, and cultural factors may be relevant. Our theoretical arguments are not country specific, but in a risk-averse country such as Mexico (Hofstede, 2001), employees might be more sensitive to the energy-draining effect of excessive workloads, such that the usefulness of resource access as a means to prevent work overload from steering employees away from productive work behaviors might be stronger than it would be in less risk-averse countries. Moreover, in this collectivistic culture, the buffering effect of relation-based resources, such as emotion sharing and organizational commitment, in protecting employees from adverse work situations may be more pronounced than in 
individualistic countries. Cross-country studies accordingly could compare the relative potency of perceptions of work overload in diminishing the propensity of creative behaviors, as well as the importance of the underlying moderators in this process, across different countries.

\section{Conclusion}

Drawing on the JD-R model, this study investigates when employees' exposure to excessive workloads is less likely to reduce their creative behavior. The likelihood that unrealistic time pressures and deadlines curtail the development of new ideas that otherwise could improve the current organizational situation decreases to the extent that employees are passionate about their work, share their emotions with colleagues, and feel strongly committed to their organization. These resources increase employees' ability and motivation to cope effectively with work overload, such that their propensity to stay away from creative behaviors diminishes. Moreover, the beneficial effects of emotion sharing and organizational commitment are exacerbated when they are combined with a strong passion for work. We hope that this study can serve as a catalyst for further investigations of how organizations can mitigate the risk that significant workplace adversity within their ranks will curtail their creative activities. 


\section{References}

Aiken, L.S., \& West, S.G. (1991). Multiple regression: Testing and interpreting interactions. Newbury Park, CA: Sage.

Aleksic, D., \& Mihelic, K.K., Cerne, M., \& Skerlavaj, M. (2017). Interactive effects of perceived time pressure, satisfaction with work-family balance (SWFB), and leader-member exchange (LMX) on creativity. Personnel Review, 46, 662-679.

Altaf, A., \& Awan, M.A. (2011). Moderating effect of workplace spirituality on the relationship of job overload and job satisfaction. Journal of Business Ethics, 104, 93-99.

Amabile, T. M. (1996). Creativity in context. Boulder, CO: Westview.

Andrews, J., \& Smith, D. C. (1996). In search of the marketing imagination: Factors affecting the creativity of marketing programs for mature products. Journal of Marketing Research, 33, 174-187.

Avery, D. R., Tonidandel, S., Volpone, S. D., \& Raghuram, A. (2010). Overworked in America? How work hours, immigrant status, and interpersonal justice affect perceived work overload. Journal of Managerial Psychology, 25, 133-147.

Avey, J. B., Luthans, F., \& Youssef, C. M. (2010). The additive value of psychological capital in predicting workplace attitudes and behaviors. Journal of Management, 36, 430-452.

Baer, M., \& Oldham, G. R. (2006). The curvilinear relation between experienced creative time pressure and creativity: moderating effects of openness to experience and support for creativity. Journal of Applied Psychology, 91, 963-970.

Bakker, A.B., \& Demerouti, E. (2007). The job demands-resources model: State of the art. Journal of Managerial Psychology, 22, 309-328.

Bakker, A. B., Demerouti, E., \& Euwema, M. C. (2005). Job resources may buffer the impact of job demands on burnout. Journal of Occupational Health Psychology, 10, 170-180.

Bakker, A.B., \& Xanthopoulou, D. (2013). Creativity and charisma among female leaders: the role of resources and work engagement. The International Journal of Human Resource Management, 24, 2760-2779.

Baum, J.R., \& Locke, E.A. (2004). The relationship of entrepreneurial traits, skill, and motivation to subsequent venture growth. Journal of Applied Psychology, 89, 587-598.

Binnewies, C., \& Wörnlein, S.C. (2011). What makes a creative day? A diary study on the interplay between affect, job stressors, and job control. Journal of Organizational Behavior, 32, 589-607.

Binyamin, G., \& Carmeli, A. (2010). Does structuring of human resource management processes enhance employee creativity? The mediating role of psychological availability. Human Resource Management, 49, 999-1024.

Bouckenooghe, D., De Clercq, D., \& Deprez, J. (2014). Interpersonal justice, relational conflict, and commitment to change: The moderating role of social interaction. Applied Psychology: An International Review, 63, 509-540.

Boyd, C. M., Bakker, A. B., Pignata, S., Winefield, A. H., Gillespie, N., \& Stough, C. (2011). A longitudinal test of the job demands-resources model among Australian university academics. Applied Psychology: An International Review, 60, 112-140.

Brislin, R.W., Lonner, W., \& Thorndike, R.M. (1973). Cross-cultural research methods. New York: John Wiley \& Sons.

Buchanan, D., \& Badham, R. (1999). Politics and organizational change: The lived experience. Human Relations, 52, 609-629. 
Castro, F. Gomes, J., \& de Sousa, FC. (2012). Do intelligent leaders make a difference? The effect of a leader's emotional intelligence on followers' creativity. Creativity and Innovation Management, 21, 171-182.

Chen, M. H., Chang, Y. Y., \& Chang, Y. C. (2015). Exploring individual-work context fit in affecting employee creativity in technology-based companies. Technological Forecasting and Social Change, 98, 1-12.

Chen, M.-H., \& Kaufmann, G. (2008). Employee creativity and R\&D: A critical review. Creativity and Innovation Management, 17, 71-76.

Coelho, F., Augusto, M., \& Lages, L.F. (2012). Contextual factors and the creativity of frontline employees: The mediating effects of role stress and intrinsic motivation. Journal of Retailing, 87, 31-45.

Colquitt, J.A., Conlon, D.E., Wesson, M.J., Porter, C.O.L.H., \& Ng, K.Y. (2001). Justice at the millennium: A meta-analytic review of 25 years of organizational justice research. Journal of Applied Psychology, 86, 425-445.

Covin, J. G., Green, K. M., and Slevin, D. P. (2006). Strategic process effects on the entrepreneurial orientation-sales growth rate relationship. Entrepreneurship Theory \& Practice, 30, 57-81.

Dawson, J.F., \& Richter, A.W. (2006). Probing three-way interactions in moderated multiple regression: Development and application of a slope difference test. Journal of Applied Psychology, 91, 917-926.

Dayan, M., \& Di Benedetto, C. (2011). Team intuition as a continuum construct and new product creativity: The role of environmental turbulence, team experience, and stress. Research Policy, 40, 276-286.

De Clercq, D., \& Belausteguigoitia, I. (2017a). Overcoming the dark side of task conflict: Buffering roles of transformational leadership, tenacity, and passion for work. European Management Journal, 35, 78-90.

De Clercq, D., \& Belausteguigoitia, I. (2017b). Mitigating the negative effect of perceived organizational politics on organizational citizenship behavior: Moderating roles of contextual and personal resources. Journal of Management and Organization, 23, 689708.

De Clercq, D., \& Belausteguigoitia, I. (2017c). The usefulness of tenacity in spurring problem-focused voice: The moderating roles of workplace adversity. Journal of Business and Psychology, 32, 479-493.

De Clercq, D., Castañer, X., \& Belausteguigoitia, I. (2011). Entrepreneurial initiative selling within organizations: Towards a more comprehensive motivational framework. Journal of Management Studies, 48, 1269-1290.

De Clercq, D., Dimov, D., \& Belausteguigoitia, I. (2016). Perceptions of adverse work conditions and innovative behavior: The buffering roles of relational resources. Entrepreneurship Theory and Practice, 40, 515-542.

De Clercq, D., Dimov, D., \& Thongpapanl, N. (2010). The moderating impact of internal social exchange processes on the entrepreneurial orientation-performance relationship, Journal of Business Venturing, 25, 87-103.

Faul, F., Erdfelder, E., Lang, A.G., \& Buchner, A. (2007). G*Power. A flexible statistical power analysis program for the social, behavioral and biomedical sciences. Behavior Research Methods, 39, 175-191. 
Ferris, G.R., Perrewé, P.L., Anthony, W.P., \& Gilmore, D.C. (2000). Political skill at work. Organizational Dynamics, 28, 25-37.

Frederiksen, M.H., \& Knudsen, M.P. (2017). From creative ideas to innovation performance: The role of assessment criteria. Creativity and Innovation Management, 26, 60-74.

Gong, Y., Huang, J.-C., \& Farh, J.-L. (2009). Employee learning orientation, transformational leadership, and employee creativity: The mediating role of employee creative self-efficacy. Academy of Management Journal, 52, 765-778.

Hakanen, J. J., Bakker, A. B., \& Demerouti, E. (2005). How dentists cope with their job demands and stay engaged: The moderating role of job resources. European Journal of Oral Sciences, 113, 479-487.

Ho, V.T., Wong, S., \& Lee, C.H. (2011). A tale of passion: Linking job passion and cognitive engagement to employee work performance. Journal of Management Studies, 48, 26-47.

Hofstede, G. (2001). Culture's consequences: Comparing values, behaviors, institutions and organizations across nations, $2^{\text {nd }}$ ed. Thousand Oaks, CA: Sage Publications.

Hon, A.H.Y., Bloom, M., \& Crant, J.M. (2014). Overcoming resistance to change and enhancing creative performance. Journal of Management, 40, 919-941.

Huang, X., Hsieh, J. J., \& He, W. (2014). Expertise dissimilarity and creativity: The contingent roles of tacit and explicit knowledge sharing. Journal of Applied Psychology, 99, 816-830.

Janssen, O. (2001). Fairness perceptions as a moderator in the curvilinear relationships between job demands, and job performance and job satisfaction. Academy of Management Journal, 44, 1039-1050.

Kim, T.-Y., Hon, A.H., \& Crant, J.M. (2009). Proactive personality, employee creativity, and newcomer outcomes: A longitudinal study. Journal of Business and Psychology, 24, 93-103.

Kobe, C., \& Goller, I. (2009). Assessment of product engineering creativity. Creativity and Innovation Management, 18, 132-140.

Lahiri, S., Pérez-Nordtvedt, L., \& Renn, R.W. (2008). Will the new competitive landscape cause your firm's decline? It depends on your mindset. Business Horizons, 51, 311-320.

Lattin, J.M., Carroll, J.D., \& Green, P.E. (2003). Analyzing multivariate data. Belmont, CA: Thomson Brooks/Cole.

Ma, Z., Long, L., Zhang, Y., Zhang, J., \& Lam, C.K. (2017). Why do high-performance human resource practices matter for team creativity? The mediating role of collective efficacy and knowledge sharing. Asia Pacific Journal of Management, 34, 565-586.

Maimone, F., \& Sinclair, M. (2014). Dancing in the dark: Creativity, knowledge creation and (emergent) organizational change. Journal of Organizational Change Management, 27, 344361.

Meyer, J. P. \& Allen, N. J. (1991). A three-component conceptualization of organizational commitment. Human Resource Management Review, 1, 61-89.

Meyer, J. P., Becker, T.E., \& Vandenberghe, C. (2004). Employee commitment and motivation: A conceptual analysis and integrative model, Journal of Applied Psychology, 89, 991-1007.

Morris, M.W., \& Keltner, D. (2000). How emotions work: The social functions of emotional expression in negotiations. Research in Organizational Behavior, 22, 1-50.

Ocker, R.J. (2005). Influences on creativity in asynchronous virtual teams: A qualitative analysis of experimental teams. IEEE Transactions on Professional Communication, 48, 22-39.

Ohly, S., \& Fritz, C. (2010). Work characteristics, challenge appraisal, creativity, and proactive behavior: A multi-level study. Journal of Organizational Behavior, 31, 543-565. 
Ohly, S., Sonnentag, S., \& Pluntke, F. (2006). Routinization, work characteristics and their relationships with creative and proactive behaviors. Journal of Organizational Behavior, 27, 257-279.

Oltra, V., \& Vivas-López, S. (2013). Boosting organizational learning through team-based talent management: what is the evidence from large Spanish firms? The International Journal of Human Resource Management, 24, 1853-1871.

Paillé, P. (2011). Perceived stressful work, citizenship behaviour and intention to leave the organization in a high turnover environment: Examining the mediating role of job satisfaction. Journal of Management Research, 3, 1-16.

Pan, W., Sun. L.-Y., \& Chow, I.H.S. (2012). Leader-member exchange and employee creativity: Test of a multilevel moderated mediation model. Human Performance, 25, 432-451.

Payne, G.T. (2006). Examining configurations and firm performance in a suboptimal equifinality context. Organization Science, 17, 756-770.

Podsakoff, P.M., \& Organ, D.W. (1986). Self-reports in organization research: Problems and prospects. Journal of Management, 12, 532-544.

Pooja, A.A., De Clercq, D., \& Belausteguigoitia, I. (2016). Job stressors and organizational citizenship behavior: The roles of organizational commitment and social interaction. Human Resource Development Quarterly, 27, 373-405.

Porter, M.E. (1996). What is strategy? Harvard Business Review, 74, 61-81.

Quinn, R.W., Spreitzer, G.M., \& Lam, C.F. (2012). Building a sustainable model of human energy in organizations: Exploring the critical role of resources. Academy of Management Annals, 6: 337-396.

Russ-Eft, D. (2001). Workload, stress, and human resource development. Human Resource Development Quarterly, 12, 1-3.

Saks, A., Uggerslev, K.L., \& Fassina, N.E. (2007). Socialization tactics and newcomer adjustment: A meta-analytic review and test of a model. Journal of Vocational Behavior, 70, 413-446.

Schaufeli, W.B., \& Bakker, A.B. (2004). Job demands, job resources, and their relationship with burnout and engagement: A multi-sample study. Journal of Organizational Behavior, 25, 293-315.

Seibert, S.E., Kraimer, M.L., \& Crant, J.M. (2001). A longitudinal model linking proactive personality and career success. Personnel Psychology, 54, 845-874.

Seligman, M.E.P., \& Csikszentmihalyi, M. (2000). Positive psychology: An introduction. American Psychologist, 55, 5-14.

Shalley, C.E., \& Gilson, L.L. (2004). What leaders need to know: A review of social and contextual factors that can foster or hinder creativity. The Leadership Quarterly, 15, 33-53.

Son, S.Y., Cho, D.H., \& Kang, S.-W. (2017). The impact of close monitoring on creativity and knowledge sharing: The mediating role of leader-member exchange. Creativity and Innovation Management, 26, 256-265.

Soriano de Alencar, E., \& Bruno-Faria, M. (1997). Characteristics of an organizational environment which stimulate and inhibit creativity. Journal of Creative Behavior, 3, 271281.

Spector, P.E. (2006). Method variance in organizational research: Truth or urban legend? Organizational Research Methods, 9, 221-232.

Spreitzer, G., Porath, C.L., \& Gibson, C.B. (2012). Toward human sustainability: How to enable more thriving at work. Organizational Dynamics, 41, 155-162. 
Stephens, J. P., Heaphy, E. D., Carmeli, A., Spreitzer, G. M., \& Dutton, J. E. (2013).

Relationship quality and virtuousness: Emotional carrying capacity as a source of individual and team resilience. Journal of Applied Behavioral Science, 49, 13-41.

Uçanok, B. \& Karabati, S. (2013). The effects of values, work centrality, and organizational commitment on organizational citizenship behaviors: Evidence from Turkish SMEs. Human Resource Development Quarterly, 24, 89-129.

Unsworth, K. L., \& Clegg, C. W. (2010). Why do employees undertake creative action? Journal of Occupational and Organizational Psychology, 83, 77-99.

Vallerand, R.J., Blanchard, C., Mageau, G.A., Koestner, R., Ratelle, C., Leonard, M., Gagne, M., \& Marsolais, J. (2003). Les passions de l'âme: On obsessive and harmonious passion. Journal of Personality and Social Psychology, 85, 756-767.

Van den Hooff, B., \& F.D.L. Van Weenen (2004). Committed to share: Commitment and CMC use as antecedents of knowledge sharing, Knowledge and Process Management, 11, 13-24.

Van Dijk, R., \& Van Dick, R. (2009). Navigating organizational change: Change leaders, employee resistance and work-based identities. Journal of Change Management, 9, 143-163.

Van Emmerik, I.J.H., Bakker, A.B., \& Euwema, M.C. (2009). Explaining employees’ evaluations of organizational change with the job demands-resources model. Career Development Journal, 14, 594-613.

Van Veldhoven, M. \& Meijman, T. (1994). The measurement of psychosocial job demands. Amsterdam: NIA.

Vredenburgh, D., \& He, I.Y. (2003). Leadership lessons from a conductorless orchestra. Business Horizons, 46, 19-24.

Xanthopoulou, D., Bakker, A.B., Demerouti, E., \& Schaufeli, W.B. (2007). The role of personal resources in the job demands-resources model. International Journal of Stress Management, 14, 121-141.

Youssef, C.M., \& Luthans, F. (2007). Positive organizational behavior in the workplace. Journal of Management, 33, 774-800.

Yuan, F., \& Woodman, R. W. (2010). Innovative behavior in the workplace: The role of performance and image outcome expectations. Academy of Management Journal, 53, 323342.

Zahra, S., \& Hayton, J.C. (2008). The effect of international venturing on firm performance: The moderating influence of absorptive capacity. Journal of Business Venturing, 23, 195-220.

Zhang, W., Zhang, Q., \& Song, M. (2015). How do individual-level factors affect the creative solution formation process of teams? Creativity and Innovation Management, 24, 508-524.

Zhou, J., \& George, J. M. (2001). When job dissatisfaction leads to creativity: Encouraging the expression of voice. Academy of Management Journal, 44, 682-696.

Zhou, Q., \& Pan, W. (2015). A cross-level examination of the process linking transformational leadership and creativity: The role of psychological safety climate. Human Performance, 28, 405-424. 
Figure 1. Conceptual Model

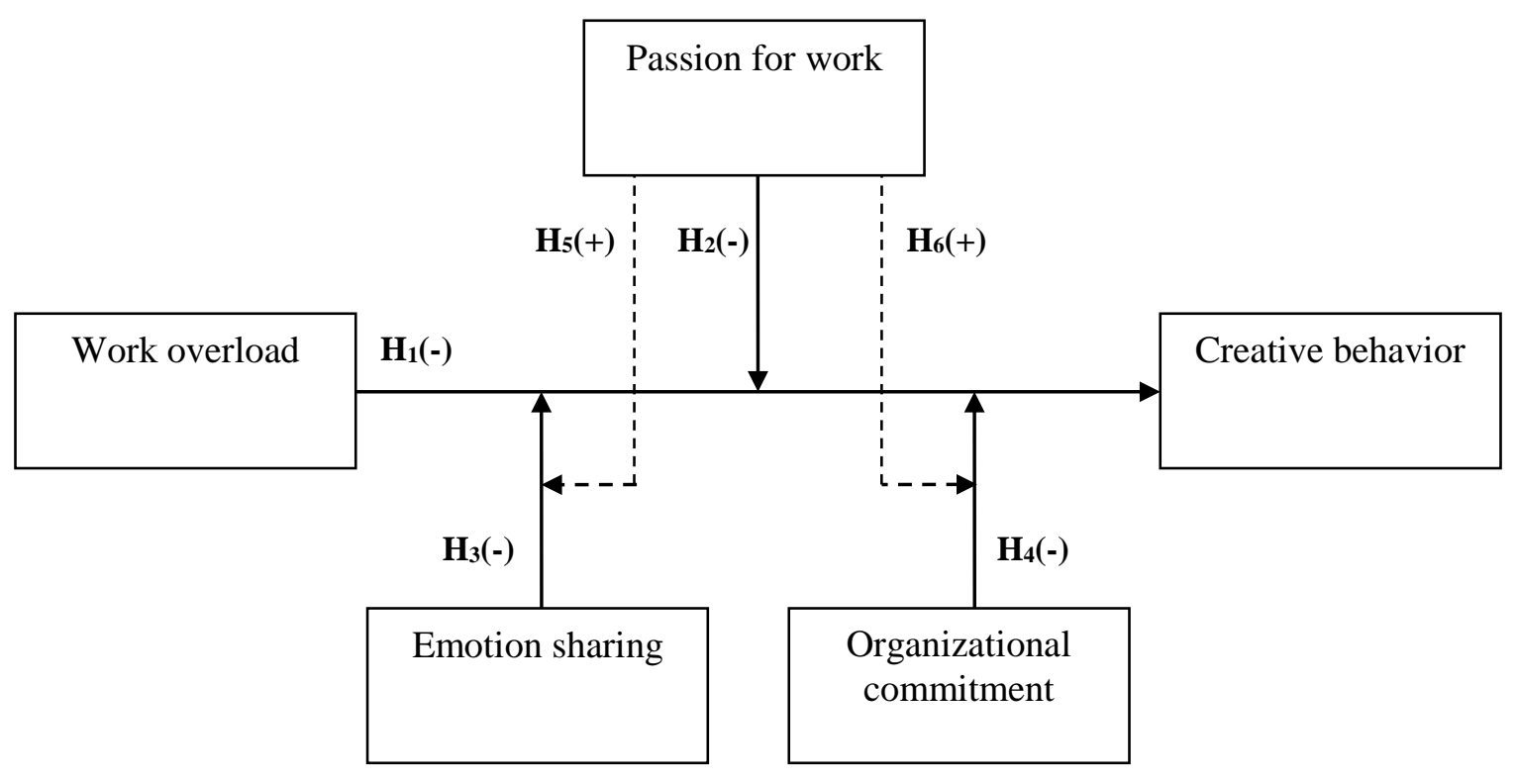


Figure 2. Two-Way Interaction Effects

A. Passion for work on the work overload-creative behavior relationship

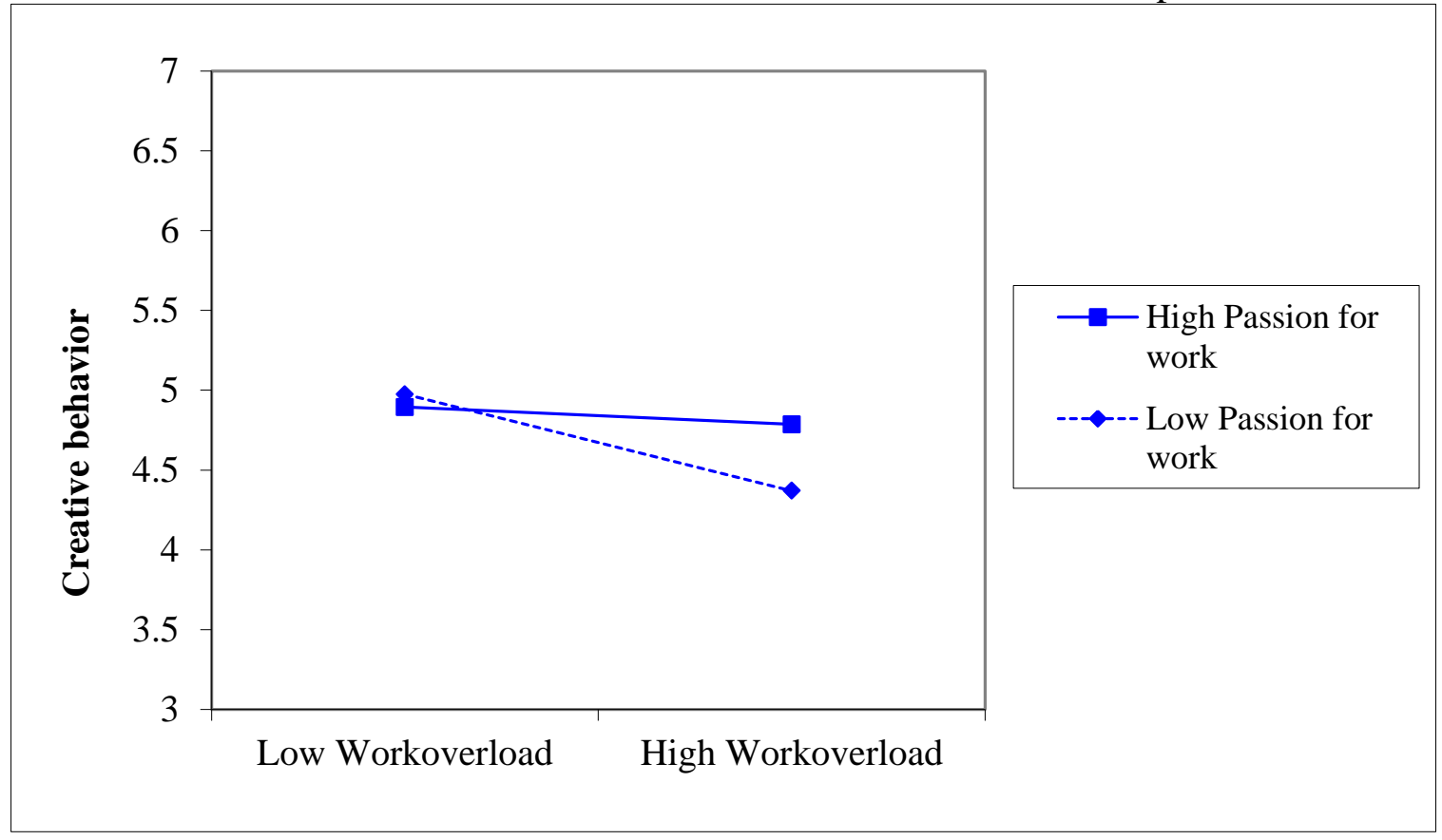

B. Emotion sharing on the work overload-creative behavior relationship

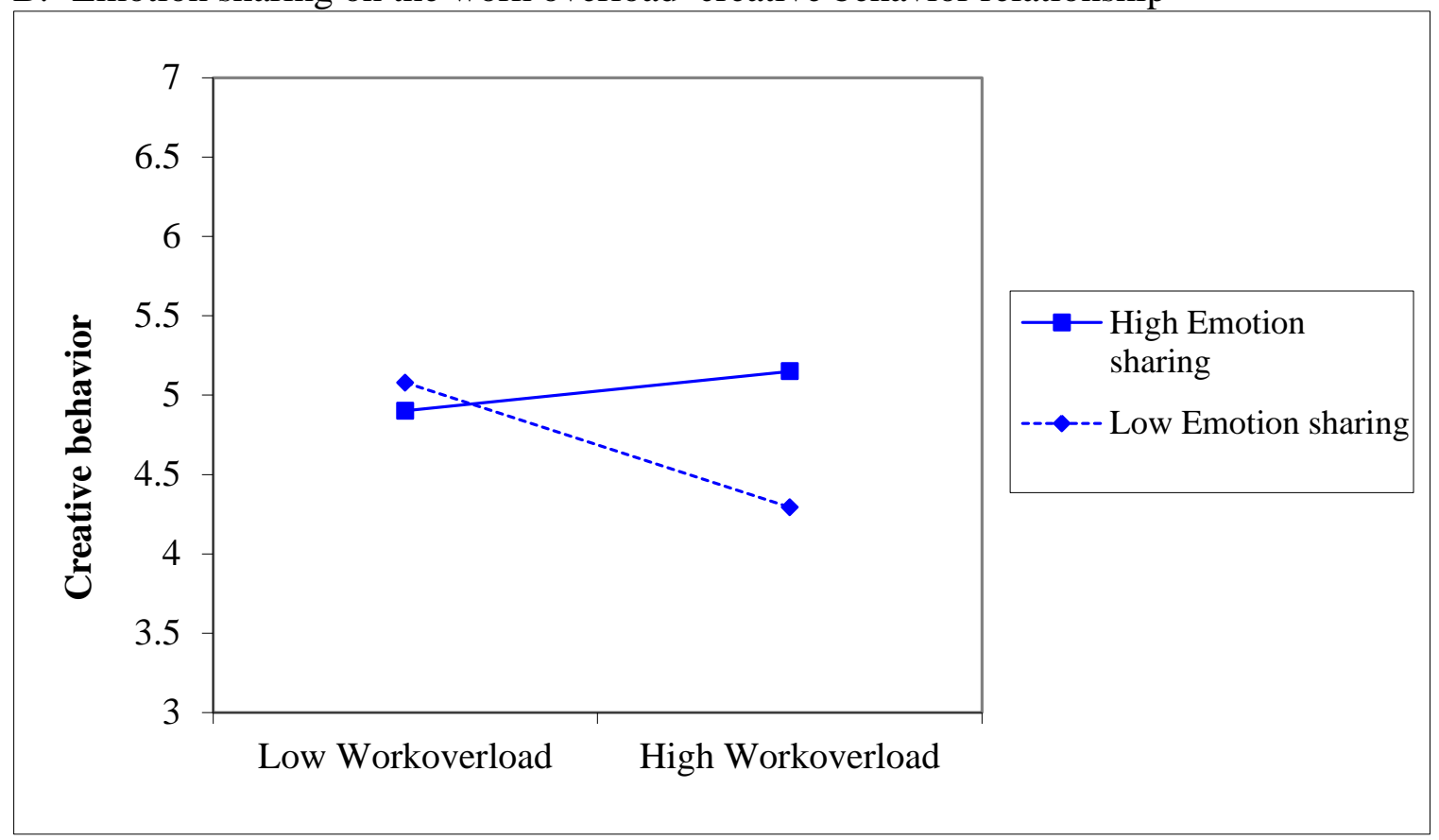


C. Organizational commitment on the work overload-creative behavior relationship

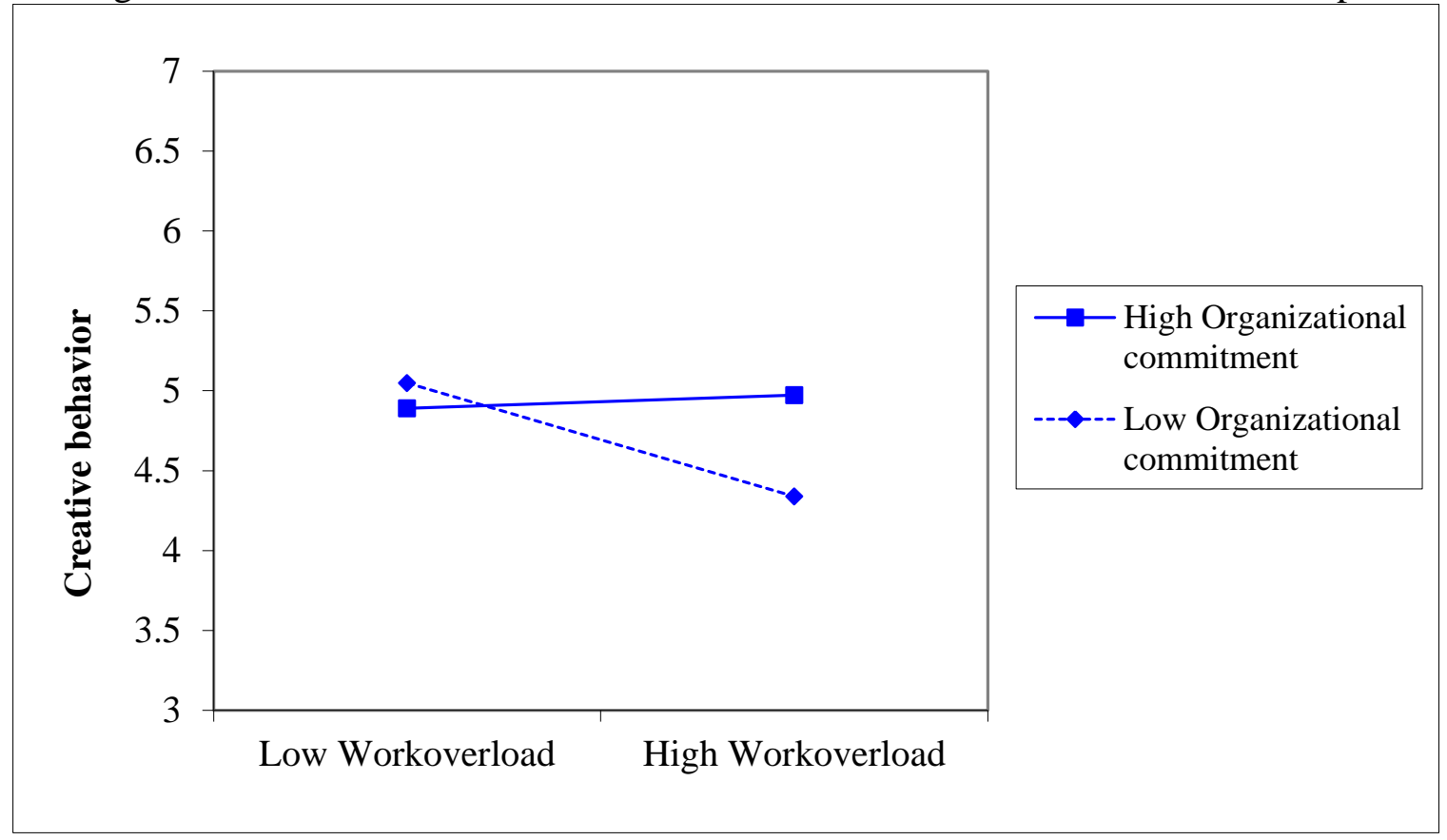


Figure 3. Three-Way Interaction Effect

A. Emotion sharing on the work overload-creative behavior relationship at high passion for work

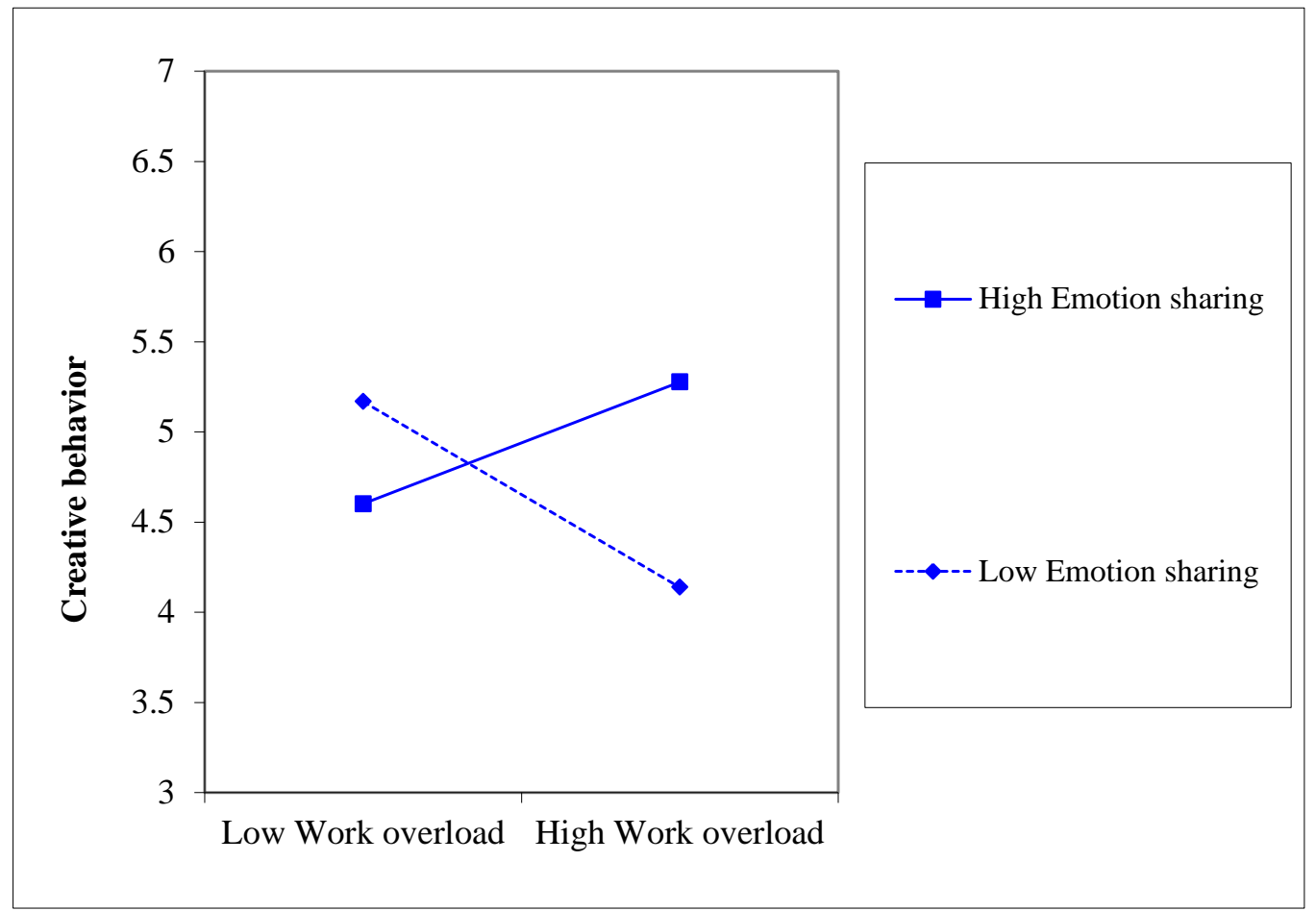

B. Emotion sharing on the work overload-creative behavior relationship at low passion for work

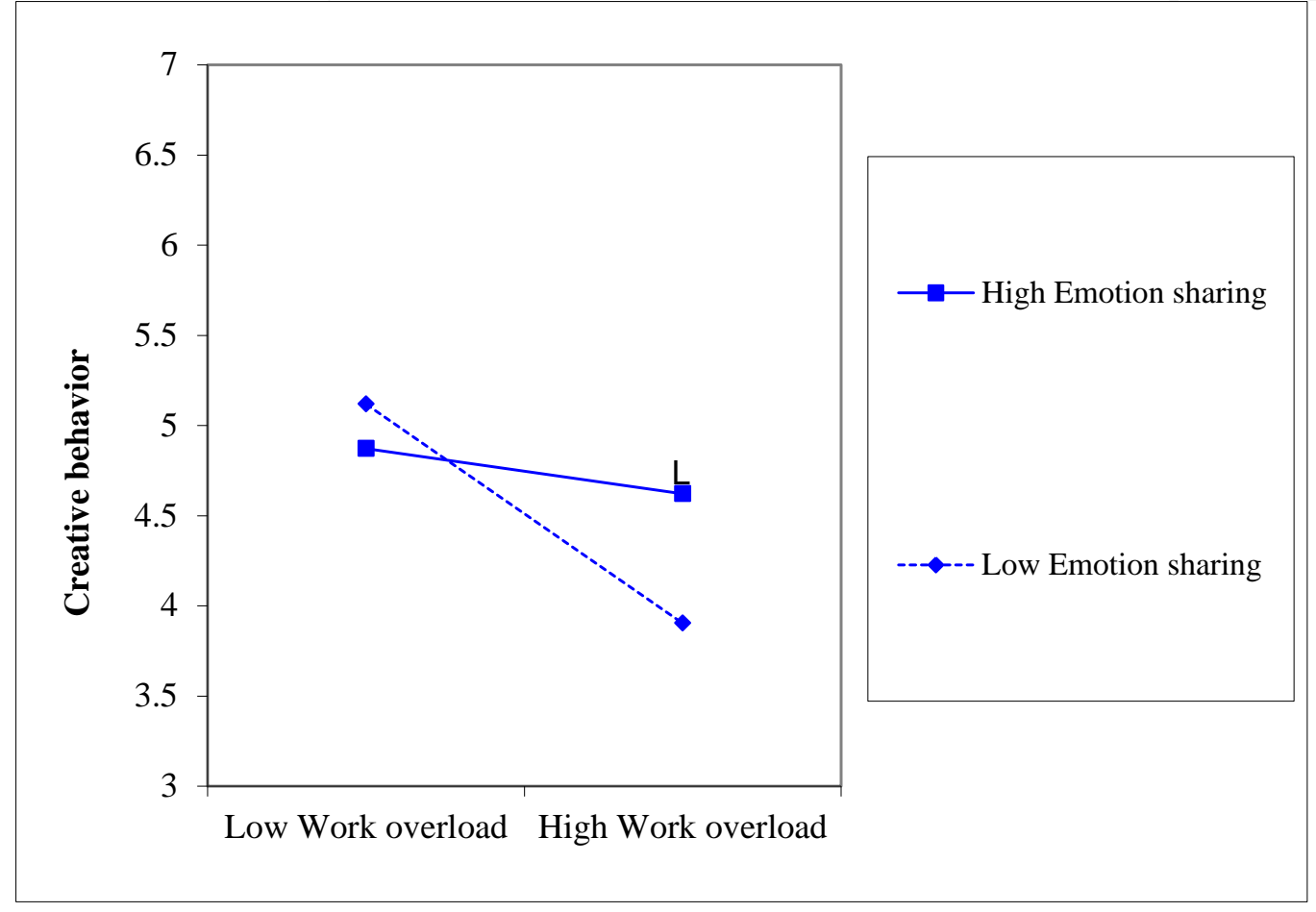


Figure 4. Three-Way Interaction Effect

A. Organizational commitment on the work overload-creative behavior relationship at high passion for work

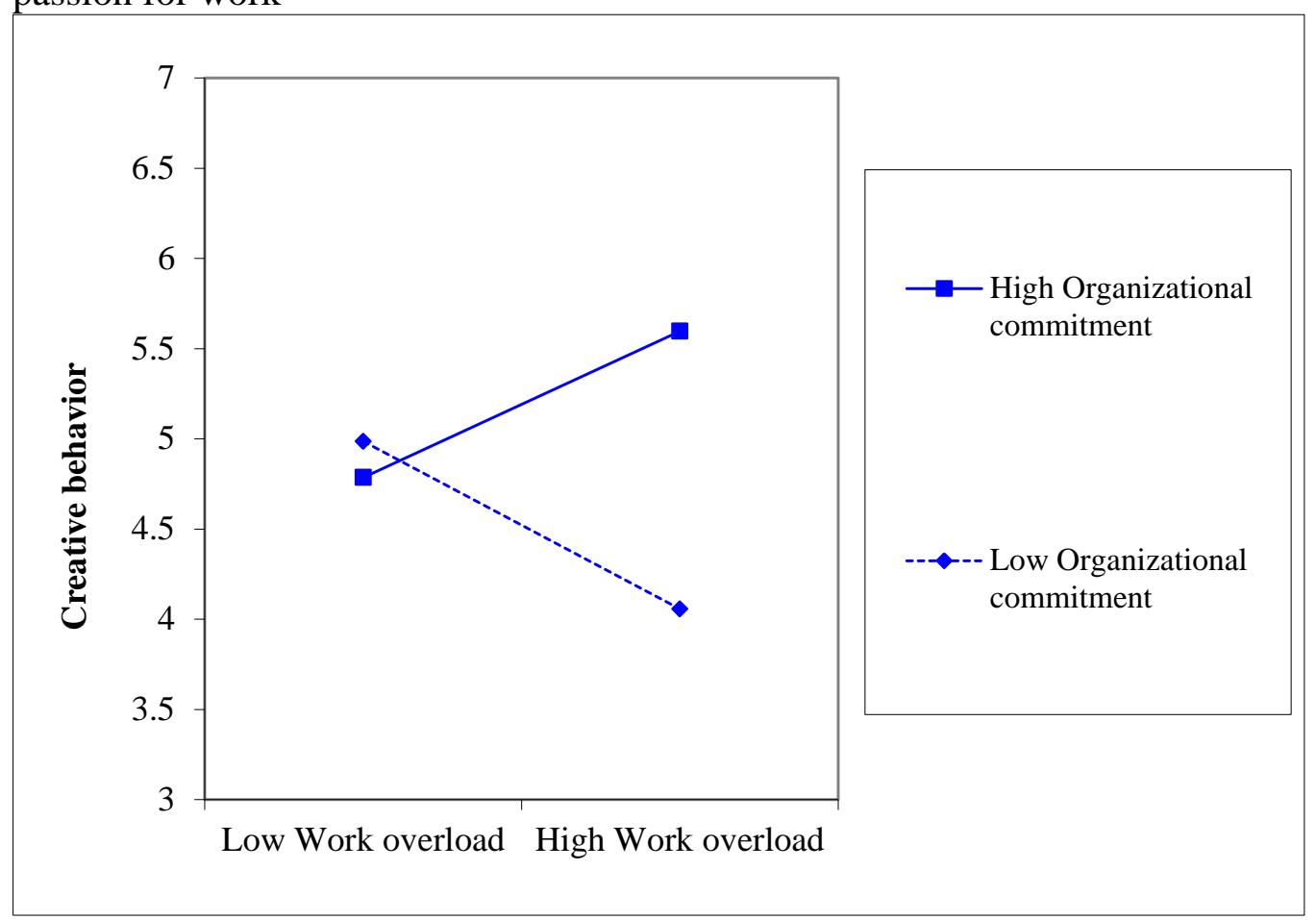

B. Organizational commitment on the work overload-creative behavior relationship at low passion for work

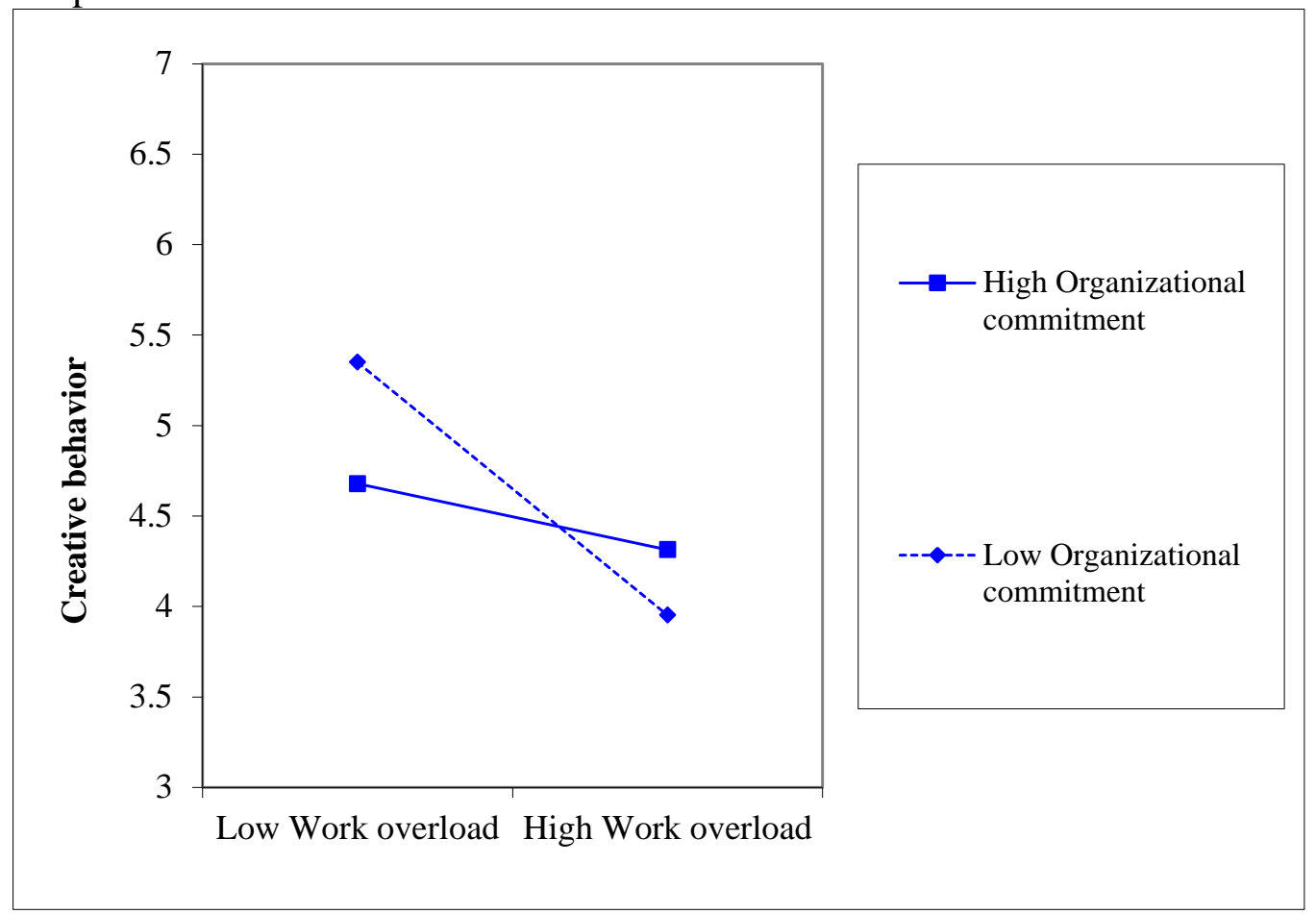


Table 1. Overview of focal constructs

\begin{tabular}{|c|c|c|}
\hline Construct & Description & Measurement items (and source) \\
\hline Creative behavior & $\begin{array}{l}\text { Generation of new ideas that } \\
\text { improve the current } \\
\text { organizational situation }\end{array}$ & $\begin{array}{l}\text { - This employee often creates new ideas for improvement. } \\
\text { - This employee often searches out new working methods, techniques, or } \\
\text { instruments. } \\
\text { - This employee often generates original solutions to problems. } \\
\text { (Janssen, 2001) }\end{array}$ \\
\hline Work overload & $\begin{array}{l}\text { Beliefs that work expectations } \\
\text { are unreasonable due to time } \\
\text { constraints }\end{array}$ & $\begin{array}{l}\text { - I often have to work too fast. } \\
\text { - I often work under time pressure. } \\
\text { - I often have to deal with a backlog at work. } \\
\text { - I often have problems with the pace of work. } \\
\text { (Janssen, 2001; Van Veldhoven \& Meijman, 1994) }\end{array}$ \\
\hline Passion for work & $\begin{array}{l}\text { Positive work energy that } \\
\text { employees possess internally }\end{array}$ & $\begin{array}{l}\text { - I love to work. } \\
\text { - I look forward to returning to work when I am away from work. } \\
\text { - I derive most of my life satisfaction from my work. } \\
\text { - I accomplish a lot at work because I love to work. } \\
\text { (Baum \& Locke, 2004) }\end{array}$ \\
\hline Emotion sharing & $\begin{array}{l}\text { Positive work energy derived } \\
\text { from exchange relationships } \\
\text { with peers }\end{array}$ & $\begin{array}{l}\text { - I can fully express my emotions to my colleagues. } \\
\text { - When my colleagues and I interact with each other, we express both } \\
\text { positive and negative feelings to each other. } \\
\text { - When I talk about my emotions with my colleagues, I feel like it is } \\
\text { constructive. } \\
\text { (Stephens et al., 2013) }\end{array}$ \\
\hline Organizational commitment & $\begin{array}{l}\text { Positive work energy achieved } \\
\text { because of how employees feel } \\
\text { about their employing } \\
\text { organization }\end{array}$ & $\begin{array}{l}\text { - I really feel the problems of the company like they are my own. } \\
\text { - I experience a strong feeling of belonging towards this company. } \\
\text { - I feel emotionally linked to this company. } \\
\text { - I feel completely integrated with the people of this company. } \\
\text { - This company means a lot to me. } \\
\text { (Meyer and Allen, 1991) }\end{array}$ \\
\hline
\end{tabular}


Table 2. Correlations and descriptive statistics

\begin{tabular}{lccccccccc}
\hline & 1 & 2 & 3 & 4 & 5 & 6 & 7 & 8 & 9 \\
\hline 1. Creative behavior & & & & & & & & & \\
2. Work overload & $-.447^{* *}$ & & & & & & & & \\
3. Passion for work & $.326^{* *}$ & $-.299^{* *}$ & & & & & & \\
4. Emotion sharing & $.423^{* *}$ & $-.338^{* *}$ & $.323^{* *}$ & & & & & \\
5. Organizational commitment & $.469^{* *}$ & $-.354^{* *}$ & $.250^{* *}$ & $.425^{* *}$ & & & & \\
6. Gender & -.063 & .133 & -.023 & -.089 & -.091 & & & & \\
7. Age & .121 & -.094 & -.057 & .163 & .049 & $-.355^{* *}$ & & & \\
8. Organizational tenure & $.265^{* *}$ & -.133 & -.148 & .104 & .154 & $-.203^{*}$ & $.548^{* *}$ & & \\
9. Job function & .082 & .066 & .091 & $.221^{*}$ & .156 & -.023 & $-.238^{*}$ & $-.197^{*}$ & \\
10. Hierarchical level & -.009 & -.017 & .068 & .037 & -.012 & $-.238^{*}$ & .075 & .126 & .061 \\
\multicolumn{1}{c}{ Mean } & 5.173 & 2.483 & 5.082 & 5.224 & 5.079 & .358 & 33.908 & 6.551 & .706 \\
& .975 & 1.300 & .974 & .790 & 1.126 & .482 & 8.912 & 5.584 & .458 \\
\hline
\end{tabular}

Note: $\mathrm{N}=109$.

${ }^{* *} p<.01 ; * p<.05$. 
Table 3. Regression results (dependent variable: creative behavior)

\begin{tabular}{|c|c|c|c|c|c|c|c|c|}
\hline & Model 1 & Model 2 & Model 3 & Model 4 & Model 5 & Model 6 & Model 7 & Model 8 \\
\hline Gender (1 = female) & -.055 & .068 & .074 & .115 & .173 & .134 & .185 & .003 \\
\hline Age & -.001 & .001 & -.003 & .001 & -.001 & .001 & .001 & .003 \\
\hline Organizational tenure & $.051 * *$ & $.042 *$ & $.040 *$ & $.037 *$ & $.036^{*}$ & $.041 * *$ & $.034 *$ & $.034 *$ \\
\hline Job function (1 = operational) & .337 & $.380 *$ & .139 & .248 & .252 & .231 & $.285^{+}$ & $.252^{+}$ \\
\hline Hierarchical level ( 1 = managerial) & -.068 & -.042 & -.048 & -.040 & -.054 & -.051 & -.004 & .009 \\
\hline $\mathrm{H}_{1}$ : Work overload & & $-.332 * *$ & $-.195 * *$ & $-.178 * *$ & $-.134 *$ & $-.157^{* *}$ & $-.175 * *$ & $-.181 * *$ \\
\hline Passion for work & & & $.146^{+}$ & .084 & .034 & .097 & .086 & $.146^{*}$ \\
\hline Emotion sharing & & & $.226 *$ & .137 & .170 & $.215^{*}$ & .165 & $.240 *$ \\
\hline Organizational commitment & & & $.181^{*}$ & $.185^{*}$ & $.200^{* *}$ & $.119^{+}$ & $.214^{* *}$ & $.114+$ \\
\hline $\begin{array}{l}\mathrm{H}_{2}: \text { Work overload } \times \text { Passion for } \\
\text { work }\end{array}$ & & & & $.124^{* *}$ & & & .110 & $.163^{* *}$ \\
\hline $\mathrm{H}_{3}$ : Work overload $\times$ Emotion sharing & & & & & $.258 * *$ & & $.325^{* *}$ & \\
\hline $\begin{array}{l}\mathrm{H}_{4}: \text { Work overload } \times \text { Organizational } \\
\text { commitment }\end{array}$ & & & & & & $.198 * *$ & & $.236 * *$ \\
\hline Emotion sharing $\times$ Passion for work & & & & & & & .016 & \\
\hline $\begin{array}{l}\text { Organizational commitment } \times \\
\text { Passion for work }\end{array}$ & & & & & & & & $.188^{* *}$ \\
\hline $\begin{array}{l}\mathrm{H}_{5}: \text { Work overload } \times \text { Emotion sharing } \\
\quad \times \text { Passion for work }\end{array}$ & & & & & & & $.093 *$ & \\
\hline $\begin{array}{l}\mathrm{H}_{6}: \text { Work overload } \times \text { Organizational } \\
\text { commitment } \times \text { Passion for work }\end{array}$ & & & & & & & & $.062 *$ \\
\hline $\mathrm{R}^{2}$ & .097 & .299 & .426 & .480 & .538 & .539 & .573 & .622 \\
\hline $\mathrm{R}^{2}$ change & & $.202^{* *}$ & $.127^{* *}$ & $.054^{* *}$ & $.112^{* *}$ & $113^{* *}$ & $.147^{* *}$ & $.196^{* *}$ \\
\hline
\end{tabular}

Note: $\mathrm{N}=109$; unstandardized coefficients (two-tailed $p$-values).

${ }^{* *} p<.01 ;{ }^{*} p<.05 ;{ }^{+} p<.1$. 